\title{
A DIFUSÃO DE PALAVRAS PORTUGUESAS, PROBLEMAS E MÉTODOS
}

\author{
Conteúdo: 0 . Nota prévia \\ 1. Introdução \\ 2. Metodologia \\ 3. Definições \\ 4. Análise \\ 5. Bibliografia \\ 7. Tabelas
}

0 . O artigo seguinte é o resumo duma conferência que proferi no ano $1983 \mathrm{em}$ Lisboa durante um congresso internacional que acompanhou a XVII Exposição Europeia da Arte, Ciência e Cultura, dedicada a 'Os Descobrimentos Portugueses e a Europa do Renascimento'. Julgo oportuno fazer conhecer o meu texto precisamente em 1988, ano comemorativo do quinto centenário quando Bartolomeu Dias dobrou o Cabo das Tormentas (hoje da Boa Esperança).

Além disso parece-me ser uma introdução útil à problemática da investigação científica da difusão de palavras portuguesas nas línguas europeias a certa época, i.e. nos séculos XVI e XVII. A complexidade deste sector da lexicologia e a necessidade de estudar dicionários de muitas línguas (e não antiquados trabalhos) se vêm claramente num pequeno artigo publicado aqui mesmo (Linguistica XXVI: F. V. Peixoto da Fonseca, A propos de l'influence de la langue portugaise, 107-113). Este autor resumiu antigas obras relativas a palavras portuguesas noutras línguas. Não queremos entrar numa discussão demasiado pormenorizada: so chamamos a atenção para alguns aspectos: Fonseca cita uma obra publicada em 1949 para enumerar os lusismos no espanhol, sem considerar os estudos posteriores dedicados ao assunto (cf. Salvador). Por isso: algumas das palavras citadas por ele já não podem ser declaradas lusismos no espanhol (cf. chaveta, chinela: no Dicionário de Corominas o autor lhes dá origem italiana por causa das datações), outras só pertencem a registos linguísticos marginais (não à língua-padrão espanhola - p.ex. chamada) e finalmente faltam lusismos importantes nesta lista (p.ex. chamuscar). À falta de Fonseca de não conhecer as obras apropriadas junta-se o manejo insuficiente das poucas obras citadas: a palavra alemã actual relacionada com o português feitiço é Fetisch, e não Feitiço (lusismo raro nalguns textos em 1606, substituido mais tarde pela forma francesa, divulgada no século XVIII). O estudo mais moderno sobre palavras alemãs de origim portuguesa no século XVI é da autoria de Hans J. Vermeer. 
1. Na obra 'A literatura portuguesa e a expansão ultramarina' o autor Hernâni Cidade deu a um capítulo do segundo volume o título ' $O$ que vimos e o que comunicámos ao mundo'. Quero tentar expôr dentro da disciplina científica que eu represento, a filologia românica, quais as palavras que 'os Portugueses comunicaram ao mundo', ou seja às linguas europeias mais importantes nos séc. XVI e XVII. Este fenómeno de 'transferencia' lexical pode ser examinado e explicado sob três pontos de vista:

a) do tempo (aspecto diacrónico ou cronológico)

b) do espaço (aspecto diatópico ou geográfico)

c) do registo (aspecto diastrático ou social).

A finalidade do meu trabalho é - baseando-me nas obras indicadas na bibliografia - indicar por quem e quando durante os séc. XVI e XVII uma palavra portuguesa foi pela primeira vez empregue nas outras línguas.

2. Para obter as informações necessárias procedeu-se do seguinte modo: num dicionário português (Dicionário da Língua Portuguesa) verificou-se quais as palavras de origem exótica aí registadas.

Com base neste primeiro passo foi elaborada uma lista com algumas centenas de palavras. Estas palavras foram controladas em dicionários de 6 línguas europeias. Se então uma destas palavras se encontra atestada numa das línguas - espanhol, italiano, francês, alemão, inglês e holandês - no séc. XVI e no início do séc. XVII foi incluída na análise. Pode evidentemente ter-se dado o caso que alguns lusismos não tenham sido identificados. Existe uma série de palavras provenientes da área de contacto das línguas sul-americanas tupi e guarani. Nos dicionários portugueses são consideradas importação directa do tupi, nos dicionários espanhóis importação directa do guarani. Dado que na costa oriental da América do Sul se encontravam também navegadores franceses das Antilhas, os dicionários franceses pretendem muitas vezes comprovar que uma palavra passou da língua indígena directamente ao francês via Antilhas, não tendó sido transmitida nem pelo espanhol nem pelo português (Wartburg, Vol. 20). Sobressai ainda que na maior parte das línguas europeias as palavras exóticas são consideradas importação directa quando a primeira datação é posterior a cerca de 1630 , e isto igualmente em casos em que a palavra correspondente se encontra atestada no português em data anterior. Creio que os investigadores deduzem do facto de depois do 1580 a presença marítima portuguesa ter deixado de existir ter passado a existir também um vacuo lexical. Seja como for, a primeira datação-desempenha claramente um papel no estabelecimento da etimologia.

Uma outra questão são os lusismos no castelhano (Salvador), dado que a interpenetração dos léxicos português e castelhano era muito intensiva. A quotaparte de palavras portuguesas no léxico castelhano é muito grande (cf. as listas de Corominas, vol. IV, pág. 1119 e segs.) e está relacionada com o bilinguismo dos autores portugueses de quinhentos e seiscentos. Estes lusismos espanhóis não foram, no entanto, tomados em conta nos casos em que não surgem igualmente em outras línguas europeias. 
Nestas condições o nosso trabalho será evidentemente tão bom quanto o material disponivel.

E ainda de lamentar que a língua mais importante deste período, capaz de difundir amplamente os novos conhecimentos, o latim, não esteja representada nos dicionários históricos da Península Ibérica. E que alguns textos só se conservaram exclusivamente na tradução latina: Da "Historia rerum a Societate Jesu in Oriente gestarum...", primitivamente escrita em português, não existe a versão vernácula. Também "Os Colóquios" de Garcia da Orta foram latinizados e depois impressos muitas vezes (Silva Dias, pág. 107 seg.).

A estas palavras foram acrescentados por mim lusismos nas línguas europeias que existiam há muito no português e que, portanto, não têm directamente a ver com os Descobrimentos. Tornaram-se, porém, conhecidas fora de Portugal - convém acentuá-lo - porque foram difundidas conjuntamente com as informações sobre as viagens de descobrimento.

3. O que é um lusismo? A resposta não é simples. Sensu stricto designa-se por lusismo uma palavra que uma língua importou directamente do português.

Ao analisar os diversos dicionários é preciso, porém, ver que também se designa por lusismo uma palavra que o próprio português recebeu e que por vezes não foi transmitida directamente pelo português, mas sim através do latim ou ainda frequentemente do italiano. A palavra portuguesa sargaço é um derivado do latim $s a$ lix e sofreu um alargamento semântico para 'planta marinha'. Esta palavra entrou no francês por 9 vias diferentes (Arveiller): primeiro foi traduzido um texto holandês (sargasso 1601). Em 1602 surge a tradução francesa de um livro latino (sargaço). Em 1610 a tradução latina do texto holandês é vertida para francês (sargassi). Uma nova tradução do texto latino já traduzido em 1610 traz em 1615 sargaço. Em 1604 um texto português é igualmente traduzido para francês (sargasso). Em 1611 mais um texto português, etc. etc. Só em 1633 existe numa tradução do inglês a palavra na grafia ainda hoje usual sargasse. Até ao séc. XVIII são usadas as várias formas e é só com os dicionários científicos de séc. XVIII que se chega a uma uniformação. Será então o francês sargasse um lusismo, um holandesismo, um latinismo ou um anglicismo?

A palavra sargaço é uma derivação do português, a forma base é em todo o caso portuguesa. Mais problemática é a definição pouco exacta no caso de palavras exóticas: a palavra banana foi levada pelos portugueses da África para a América. Das Antilhas veio para a Europa. Será banana nas linguas europeias um lusismo?

A palavra chá vulgarmente usada em português é de origem asiática. Actualmente esta forma está reduzida ao português; mas no fỉm do séc. XVI e na Ia metade do séc. XVII a forma portuguesa estava bastante difundida: entrou no francês pelo italiano (cia 1589) e também pelo latim (chia 1603), antes de ser substituida pela for- 
ma holandesa te (1633). A palavra cia no francês de 1590 será um italianismo, um lusismo ou uma palavra asiática?

No francês à actual palavra mousson é atribuida origem portuguesa. Em 1602 surge, porém, no francês a forma monsson numa tradução do neerlandês, sendo este texto originariamente português. Em 1608 um texto português é traduzido directamente para francês; em 1622 um texto espanhol, no qual aparece pela primeira vez mousson. A partir de 1633 esta forma surge com mais frequência, passando assim a ser a única grafia oficial. Terá provavelmente sido uma gralha (Arveiller 345).

Alarguei-me nestes exemplos para mostrar que a procura de lusismos nas línguas europeias é não só uma tarefa árdua e trabalhosa, mas também apresenta inúmeros problemas terminológicos.

4. Passemos agora à análise de uma parte do material indicado nas listas (43 palavras). Existem vários critérios segundo os quais as palavras podem ser sistematizadas.

Segundo a origem 19 das palavras portuguesas provêm da Ásia, principalmente de línguas indianas, 11 da América do Sul. Tratase exclusivamente de substantivos, 9 palavras são derivações portuguesas ou importações do espanhol e do italiano. 24 das palavras de origem exótica (de 34 ) designam animais e plantas. Outras palavras referem-se a particularidades regionais: bonzo, rajá, pagode, pária.

Acontece ainda que palavras anteriormente existentes no português sofrem uma modifição semântica em virtude dos Descobrimentos. Por ex. a palavra casta existe já anteriormente, depois de 1516 é difundida em toda a Europa com o significado de 'classe social na Índia'.

Os Portugueses tomaram conhecimento na Ásia de uma tempestade particularmente forte a que deram o nome de tufão. Quando esta palavra veio para França via Itália foi contaminada pela palavra typho existente já no autor latino Plínio. A grafia clásica representa assim un fenómeno dado a conhecer pelos portugueses ( $t y$ phon).

No que diz respeito à listagem cronológica as datas indicadas são meros pontos de orientação e de modo nenhum dados absolutamente seguros. O lusismo "marmalade" existe no inglês escrito, desde o ano de 1480 , enquanto que a forma originaria portuguesa é documentada 40 anos mais tarde. Enquanto que no italiano a primeira datação para banana é de 1591 , encontramos com data anterior representações do fruto nas paredes do palácio Pitti de Florença onde foram pintadas em 1588. Este exemplo mostra que as primeiras datações só com muito cuidado devem ser utilizadas na argumentação científica (vd. supra). 
As palavras portuguesas distribuem-se cronológicamente do seguinte modo: antes de 1500 encontram-se atestadas 3 , até 155014 palavras, até 160014 . A distribuição das palavras espanholas correspondentes é a seguinte: 2 são da 1 a metade do Séc. XVI, 6 da 2 a metade e o resto é muito posterior, com excepção de palavras já há muito tempo existentes, mas somente no séc. XVI difundidas na forma portuguesa. Eis o caso de caravela, invenção genovesa, cujo nome já está atestado num documento latino de 1230 . Isto aconteceu também com as palavras laca e casta.

Mesmo uma palavra como bambu, unânime aceite como lusismo em todos os dicionários etimológicos, está documentada no catalão muito cedo, no ano de 1489 , na forma vambó, certamenta transmitida por fontes árabes. Será erróneo concluir da divergência cronológica entre o espanhol e o português estarem os espanhóis pior informandos dos descobrimentos portugueses. A verdade é que a falta de um bom dicionário histórico causa problemas lamentáveis.

Qual é a situação das primeiras datações italianas? Sabemos todos que os comerciantes e representantes bancários italianos em Portugal tinham também outra função muito importante: a da espionagem. Era seu dever relatar todas as novidades acontecidas durante as viagens dos navios portugueses. Bastará dizer que um dos primeiros mapas, o mapa Cantino, foi roubado por italianos e se conserva hoje em. Itália (Hamann). Este facto contribuiu para a conservação do mapa, pois em Portugal ter-se-ia provavelmente perdido no terramoto do séc. XVIII. Existem mesmo roteiros em italiano, traduzidos do português, tendo-se perdido o original.

Dos lusismos italianos a maior parte está documentada na $2^{\text {a }}$ metade do séc. XVI.

Para o francês constatamos 7 lusismos na $1^{\text {a }}$ metade do séc. XVI, 15 na $2^{\text {a }}$ e o resto no séc. XVII.

Vemos então uma diferença bastante grande entre lusismos franceses e os lusismos nas outras línguas. Claro está, isto mostra bem o estado - muito deficiente da pesquisa etimológica de cada língua românica. Creio poder dizer aqui que a etimologia não é auto-suficiente para esclarecer todos os processos etimológicos duma palavra. Por exemplo, a palavra mais, atestada muito cedo em espanhol, aparece bastante mais tarde nas outras línguas europeias. Mas já entre 1516 e 1519 podemos ver estas novas plantas num livro dedicado ao imperador Maximiliano I (Kohl, pág. 25). A história de uma palavra deve por isso ser reconstruida não só pelos investigadores linguísticos, mas também em conjunto com os historiadores da arte.

Não falei ainda dos lusismos ingleses e alemães: para os avaliar duma maneira suficientemente objectiva devemos recordar que os ingleses e os holandeses conquistaram muitas terras portuguesas no fim do séc. XVI e no séc. XVII. Trouxeram também para a Europa novas coisas e os seus nomes que muitas vezes substituiram a palavra portuguesa já existente. Parece que mesmo o português trocou uma palavra 
própria por uma palavra inglesa: no francês encontramos pelo ano de 1611 a palavra atollon no sentido moderno de 'atol'. Os lexicógrafos franceses dizem que a forma atollon é tomada do português, onde eu pessoalmente não a encontrei. Depois da conquista desta parte do mundo, das Maldivas, pelos ingleses estes tomaram também a palavra na forma atol universalmente difundida na Europa e até no português.

A palavra berbere, 'doença' tomada pelos portugueses na Índia foi difundida na Europa; no francês encontramos já no ano de 1617 a forma barbères. Quando os holandeses se expandiram no Oceano Índico tomaram a mesma palavra que num livro traduzido para latim recebeu a forma beri-beri que desde 1686 está documentada em francềs.

Interessantíssima é ainda a substituição do lusismo chá. A palavra chinesa atestada em português em 1565 propagou-se em muitas línguas. Está presente no espanhol desde 1610 , no italiano e no francês já na $2^{a}$ metade do sec. XVI. A forma actual em francês thé, no inglês tea, no alemão Tee, é documentada depois de 1650 como holandesismo.

O. alemão de hoje conhece também a maior parte destes lusismos, mas houve igualmente uma época em que os puristas tentaram eliminar os estrangeirismos e suplantá-los por traduções (como também aconteceu no italiano: tomate é pomodoro).

No alemão o ananás conhecia-se pelo nome de Königsapfel (quer dizer 'maçã do rei'), a banana pelo Adamsapfel (maçã de Adão), etc. A investigação deste fenómeno é na minha opinião um grande desideratum.

Quero chegar ao fim da minha comunicação: falei da difusão dos lusismos no tempo e no espaço. Ainda não falei dos níveis linguísticos: quando visitamos um mercado vemos todos os frutos, no jardim zoológico encontramos os animais, cujos nomes foram dados pelos portugueses. Mas nem sempre foi assim. Entre o grande público o ananás não era conhecido até ao séc. XX. Só os botânicos falavam anteriormente dele. A literatura de viagens, por nós bem conhecida, não foi lida por causa dos frutos nem dos animais, mas por outras razốes, por exemplo interesses comerciais ou politico-militares. O preço dum livro no séc. XVI era tão elevado que só poucos podiam comprá-lo. Uma grande parte destas palavras só foi ressuscitada no séc. XVIII pelos botânicos e zoólogos interessados na sistematiçazão dos fenómenos naturais (Linné, etc.). O facto de palavras terem ficado retidas até ao séc. XIX na literatura científica pode também documentar-se pela conservação da forma original, não alterada. A fonética destas palavras não participou da evolução da língua quotidiana sujeita ao uso de gente sem instrução. Nenhuma das palavras mencionadas tem uma frequência elevada na língua do dia a dia, nem na língua literária. Podemos controlá-lo infelizmente só para uma língua: para o francês exịste um dicionário de frequências que contém cerca de 32 milhões de palavras: claro está, que as 
palavras funcionais, sem sentido próprio, como os artigos, as preposições ocupam os primeiros lugares: frequências de $\mathbf{4 0 0 . 0 0 0 ~ s a ̃ o ~ n a t u r a i s . ~ Q u a ̃ o ~ r a r a ~ e ́ ~ e m ~ c o n t r a - ~}$ partida uma palavra como banana: o dicionário de frequências mostra-nos que nos textos literários franceses do séc. XIX a palavra aparece só 134 vezes, a palavra ananás só 85 vezes.

E com estas indicações, cujo objetivo foi documentar o uso actual destas palavras, dou por terminada a minha comunicação.

\section{BIBLIOGRAFIA}

R. Arveiller, Contribution à la l'étude des termes de voyage en français (1505-1722), Paris 1963.

C. Battisti-G. Alessio, Dizionario etimologico italiano, Firenze 1951.

H. Cidade, A literatura portuguesa e a expansão ultramarina, Coimbra vol. I $1963^{2}$, vol. II, 1964.

J. Corominas, Diccionario crítico etimológico de la lengua castellana, Berna 1954 ss.

J. S. da Silva Dias, Os descobrimentos e a problemática cultural do século XVI, Lisboa 1982.

Dicionario da Língua Portuguesa, Porto s.a.

Dictionnaire des Fréquences (Trésor de la langue française), Nancy 1971.

Th. Finkenstädt et al., Chronological English Dictionary, Heidelberg 1970.

G. Hamann, Der Eintritt der südlichen Hemisphäre in die europäische Geschichte, Wien 1968.

F. Kluge, Etymologisches Wörterbuch der deutschen Sprache, Berlin $1967^{20}$.

K. - H. Kohl ed., Mythen der neuen Welt, zur Entdeckungsgeschichte Lateinamerikas (Katalog), Berlin 1982.

J. P. Machado, Dicionario da Língua Portuguesa, Lisboa $1967^{2}$ ss.

D. Messner, Dictionnaire chronologique de la langue portugaise, Heidelberg 1976.

D. Messner, Répertoire chronologique des mots français, Heidelberg 1977.

D. Messner, Einführung in die Geschichte des französischen Wortschatzes, Darmstadt 1977.

D. Messner, Geschichte des spanischen Wortschatzes, eine Einführung, Heidelberg 1979.

F. Pigafetta, Description du Royaume de Congo et des Contrées environnantes, traduite de l'italien par Willy Bal, Louvain $1969^{2}$.

P. Robert, Dictionaire alphabétique et analogique de la langue française, Paris 1978.

G. Salvador, Lusismos, in: Enciclopedia Lingüística Hispanica, Madrid 1967, vol. II.

J. Veríssimo Serrão, História de Portugal, vol. II, III, Lisboa 1980.

The Shorter Oxford English Dictionary, Oxford $1974^{3}$.

H. J. Vermeer, Über einige Typen sprachlicher Interferenz in der deutschen Reisefachliteratur des 16. Jahrhunderts, in: Sprachliche Interferenz, Festschrift für 
W. Betz zum 65. Geburtstag, hrsg. v. H. Kolb-H. Lauffer, Tübingen 1977, 146ss.

Jan de Vries, Nederlands Etymologisch Woordernboek, Leiden 1971.

W. v. Wartburg, Französisches Etymologisches Wörterbuch, vol. 20, Basel 1968.

$\begin{array}{llll}\text { ABREVIAÇÕES } & & \text { ind } & \text { língua da Índia } \\ \text { al } & \text { alemão } & \text { ing } & \text { inglês } \\ \text { ar } & \text { árabe } & \text { it } & \text { italiano } \\ \text { chin } & \text { chinês } & \text { jap } & \text { japonês } \\ \text { cing } & \text { cingalês } & \text { lat } & \text { latim } \\ \text { esp } & \text { espanhol } & \text { mal } & \text { malaio } \\ \text { fr } & \text { francês } & \text { maldiv } & \text { língua das Maldivas } \\ \text { guar } & \text { guarani } & \text { pers } & \text { pérsico } \\ \text { hol } & \text { holandês } & \text { port } & \text { português }\end{array}$




\begin{tabular}{|c|c|c|c|c|c|c|}
\hline PORT & ESP & ITAL & FR & ING & HOL & AL \\
\hline ananas & ananás & ananas & ananas & ananas & ananas & Ananas \\
\hline tupi & PORT & PORT & PORT & $\mathrm{fr}$ & $\mathrm{fr}$ & PORT \\
\hline XVI & 1578 & 1583 & 1544 & 1613 & 1590 & 1590 \\
\hline $\begin{array}{l}\text { areca } \\
\text { malaiala } \\
1510\end{array}$ & areca & $\begin{array}{l}\text { areca } \\
\text { PORT } \\
1580\end{array}$ & $\begin{array}{l}\text { areca } \\
\text { it } \\
1540\end{array}$ & $\begin{array}{l}\text { areca } \\
\text { PORT } \\
1599\end{array}$ & areka & Areka \\
\hline $\begin{array}{l}\text { (atolão) } \\
\text { maldiv }\end{array}$ & atolón & & $\begin{array}{l}\text { atollon } \\
\text { PORT } \\
1611\end{array}$ & & & \\
\hline $\begin{array}{l}\text { [atol } \\
\text { ing }\end{array}$ & atol & $\begin{array}{l}\text { atollo } \\
\mathrm{fr} \\
\mathrm{XIX}\end{array}$ & $\begin{array}{l}\text { atoll } \\
\text { ing } \\
1803\end{array}$ & $\begin{array}{l}\text { atoll } \\
\text { maldiv } \\
1625\end{array}$ & atol & Atoll] \\
\hline bambu & bambú & bambì & bambou & bamboo & bamboe & Bambus \\
\hline marata & PORT & PORT & PORT & PORT & PORT & hol \\
\hline 1516 & 1609 & XVI & 1598 & 1598 & XVI & XVI \\
\hline banana & (banana & banana & banane & banana & banaan & Banane \\
\hline árabe & $\mathrm{fr}$ & PORT & PORT & PORT/esp & PORT & PORT \\
\hline 1563 & $1765)$ & 1591 & 1600 & 1597 & & 1601 \\
\hline $\begin{array}{l}\text { berbere }+ \\
\text { cing } \\
1568\end{array}$ & & & $\begin{array}{l}\text { barbère }+ \\
\text { PORT } \\
1617\end{array}$ & & & . \\
\hline $\begin{array}{l}\text { [beribéri } \\
\text { cing } \\
1617\end{array}$ & $\begin{array}{l}\text { beriberi } \\
\text { fr }\end{array}$ & $\begin{array}{l}\text { beri-beri } \\
\text { fr } \\
\text { XIX }\end{array}$ & $\begin{array}{l}\text { béribéri } \\
\text { hol } \\
1686\end{array}$ & $\begin{array}{l}\text { beríberi } \\
\text { cing } \\
1879\end{array}$ & $\begin{array}{l}\text { beri-beri } \\
\text { cing } \\
\text { XVII }\end{array}$ & $\begin{array}{l}\text { Beriberi] } \\
\text { cing }\end{array}$ \\
\hline $\begin{array}{l}\text { bétel } \\
\text { malaiala } \\
1500\end{array}$ & betel & $\begin{array}{l}\text { betel } \\
\text { PORT } \\
1583\end{array}$ & $\begin{array}{l}\text { betel } \\
\text { it } \\
1519\end{array}$ & $\begin{array}{l}\text { betle } \\
\text { PORT } \\
1533\end{array}$ & $\begin{array}{l}\text { betel } \\
\text { PORT }\end{array}$ & $\begin{array}{l}\text { Betel } \\
\text { PORT } \\
1595\end{array}$ \\
\hline $\begin{array}{l}\text { bonzo } \\
\text { jap } \\
1545\end{array}$ & $\begin{array}{l}\text { bonzo } \\
\text { PORT } \\
1618\end{array}$ & $\begin{array}{l}\text { bonzo } \\
\text { PORT } \\
\text { XVIII }\end{array}$ & $\begin{array}{l}\text { bonze } \\
\text { PORT } \\
1570\end{array}$ & $\begin{array}{l}\text { bonze } \\
\mathrm{fr} \\
1588\end{array}$ & $\begin{array}{l}\text { bons } \\
\text { fr }\end{array}$ & $\begin{array}{l}\text { Bonze } \\
\text { ing } \\
1676\end{array}$ \\
\hline $\begin{array}{l}\text { cacatua } \\
\text { malaio } \\
1630\end{array}$ & $\begin{array}{l}\text { cacatúa } \\
\text { mal } \\
\mathrm{XX}\end{array}$ & $\begin{array}{l}\text { cacatùa } \\
\text { PORT } \\
\text { XVII }\end{array}$ & $\begin{array}{l}\text { cacatoès } \\
\text { al } \\
1659\end{array}$ & $\begin{array}{l}\text { cockatoo } \\
1634\end{array}$ & $\begin{array}{l}\text { kaketoe } \\
\text { mal }\end{array}$ & $\begin{array}{l}\text { Kakadu } \\
\text { hol } \\
1669\end{array}$ \\
\hline $\begin{array}{l}\text { carambola } \\
\text { marata } \\
1563\end{array}$ & $\begin{array}{l}\text { carambola } \\
\text { PORT } \\
1578\end{array}$ & $\begin{array}{l}\text { caràmbola } \\
\text { PORT } \\
\text { XVII }\end{array}$ & $\begin{array}{l}\text { carambole + } \\
\text { PORT/esp } \\
1602\end{array}$ & $\begin{array}{l}\text { carambola } \\
\text { PORT } \\
1775\end{array}$ & , & Karambola \\
\hline $\begin{array}{l}\text { caramelo } \\
\text { esp } \\
1593\end{array}$ & $\begin{array}{l}\text { caramelo } \\
\text { PORT } \\
1611\end{array}$ & $\begin{array}{l}\text { caramella } \\
\text { esp/PORT } \\
\text { XVIII }\end{array}$ & $\begin{array}{l}\text { caramel } \\
\text { esp } \\
1680\end{array}$ & $\begin{array}{l}\text { caramel } \\
\text { fr } \\
1725 .\end{array}$ & $\begin{array}{l}\text { karamel } \\
\mathrm{fr}\end{array}$ & $\begin{array}{l}\text { Karamel } \\
\mathrm{fr}\end{array}$ \\
\hline
\end{tabular}




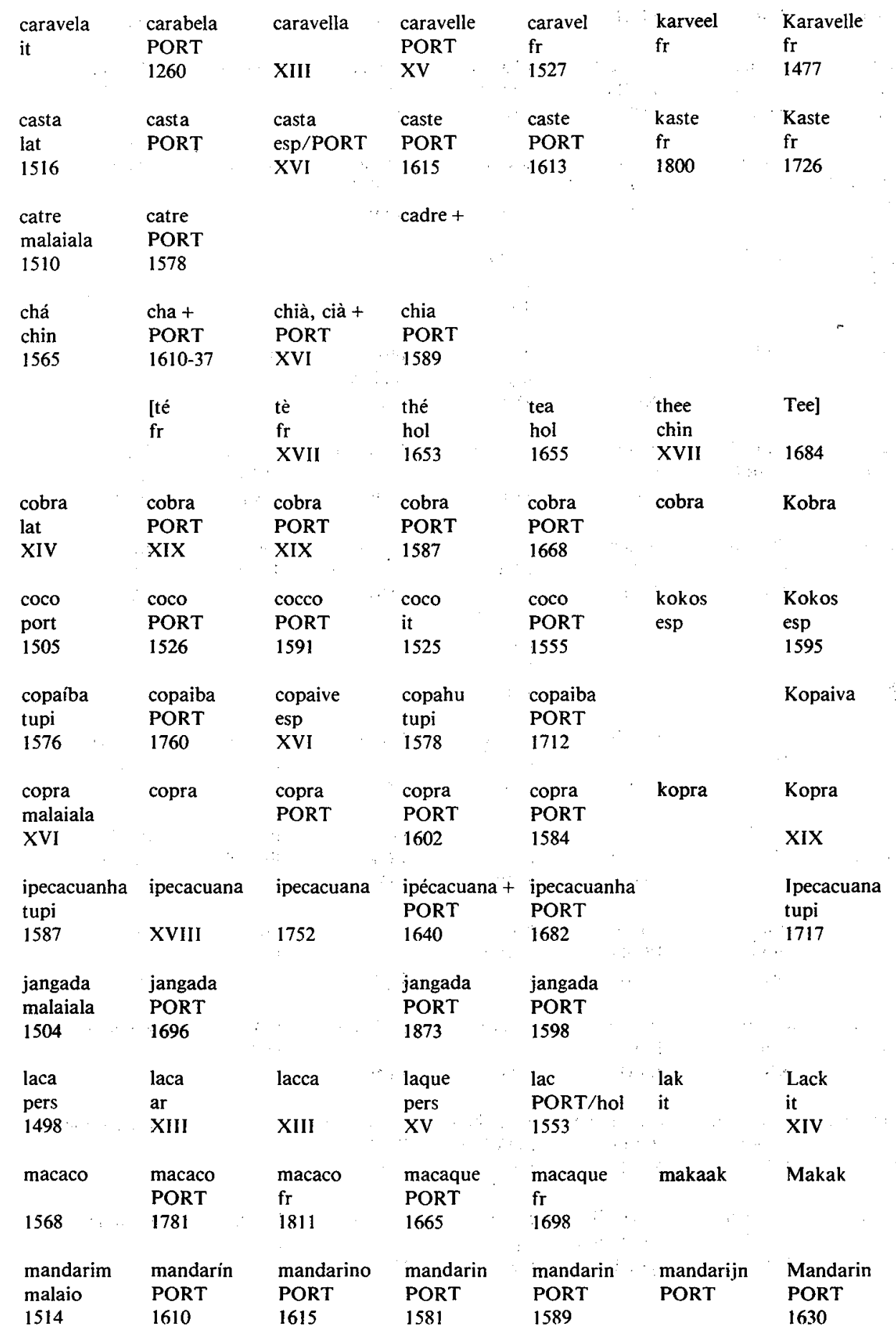




\begin{tabular}{|c|c|c|c|c|c|c|}
\hline $\begin{array}{l}\text { mandioca } \\
\text { tupi }\end{array}$ & $\begin{array}{l}\text { mandioca } \\
\text { guar }\end{array}$ & $\begin{array}{l}\text { mandioca + } \\
\text { PORT }\end{array}$ & $\begin{array}{l}\text { mandioca } \\
\text { PORT }\end{array}$ & $\begin{array}{l}\text { mandioc } \\
\text { PORT }\end{array}$ & & Mandiok \\
\hline 1526 & 1526 & 1549-XVII & 1640 & XVII & & 1556 \\
\hline & & $\begin{array}{l}\text { [manioca } \\
\text { fr } \\
1827\end{array}$ & $\begin{array}{l}\text { manioc } \\
\text { tupi } \\
1558\end{array}$ & $\begin{array}{l}\text { manioc } \\
1568\end{array}$ & $\begin{array}{l}\text { manioc } \\
\text { fr }\end{array}$ & $\begin{array}{l}\text { Maniok] } \\
1567\end{array}$ \\
\hline $\begin{array}{l}\text { mango } \\
\text { malaiala }\end{array}$ & $\begin{array}{l}\text { mango } \\
\text { ing } \\
1578\end{array}$ & $\begin{array}{l}\text { mango } \\
\text { PORT } \\
\text { XIX }\end{array}$ & $\begin{array}{l}\text { mangue } \\
\text { PORT } \\
1540\end{array}$ & $\begin{array}{l}\text { mango } \\
\text { PORT } \\
1582\end{array}$ & mango & Mango \\
\hline $\begin{array}{l}\text { marmelada } \\
\text { port } \\
1521\end{array}$ & $\begin{array}{l}\text { marmelada } \\
\text { PORT } \\
1570\end{array}$ & $\begin{array}{l}\text { marmellata } \\
\text { PORT } \\
1573\end{array}$ & $\begin{array}{l}\text { marmelade } \\
\text { PORT } \\
1573\end{array}$ & $\begin{array}{l}\text { marmelade } \\
\mathrm{fr} \\
1480\end{array}$ & $\begin{array}{l}\text { marmelade } \\
\text { fr }\end{array}$ & $\begin{array}{l}\text { Marmelade } \\
\text { esp } \\
1589\end{array}$ \\
\hline $\begin{array}{l}\text { mulato } \\
\text { port } \\
1525\end{array}$ & $\begin{array}{l}\text { mulato } \\
\text { PORT } \\
1588\end{array}$ & mulato & $\begin{array}{l}\text { mulâtre } \\
\text { esp } \\
1604\end{array}$ & $\begin{array}{l}\text { mulatto } \\
\text { esp/PORT } \\
1595\end{array}$ & $\begin{array}{l}\text { mulat } \\
\text { PORT }\end{array}$ & $\begin{array}{l}\text { Mulatte } \\
\text { esp } \\
1598\end{array}$ \\
\hline $\begin{array}{l}\text { nababo } \\
\text { ar } \\
1600\end{array}$ & $\begin{array}{l}\text { nabab } \\
\text { fr } \\
\text { XIX }\end{array}$ & $\begin{array}{l}\text { nababbo } \\
\text { ing } \\
\text { XIX }\end{array}$ & $\begin{array}{l}\text { nabab } \\
\text { PORT } \\
1614\end{array}$ & $\begin{array}{l}\text { nabob } \\
\text { PORT } \\
1612\end{array}$ & $\begin{array}{l}\text { nabob } \\
\text { PORT }\end{array}$ & $\begin{array}{l}\text { Nabob } \\
\text { ing }\end{array}$ \\
\hline $\begin{array}{l}\text { pagode } \\
\text { sânscrito } \\
1525\end{array}$ & $\begin{array}{l}\text { pagoda } \\
\text { PORT } \\
\text { XVIII }\end{array}$ & $\begin{array}{l}\text { pàgodo } \\
\text { PORT } \\
1804\end{array}$ & $\begin{array}{l}\text { pagode } \\
\text { PORT } \\
1.553\end{array}$ & $\begin{array}{l}\text { pagoda } \\
\text { PORT } \\
1618\end{array}$ & $\begin{array}{l}\text { pagode } \\
\text { PORT }\end{array}$ & $\begin{array}{l}\text { Pagode } \\
1598\end{array}$ \\
\hline $\begin{array}{l}\text { pária } \\
\text { tâmul } \\
1607(1517 ?)\end{array}$ & $\begin{array}{l}\text { paria } \\
\text { ing } \\
\text { XVIII }\end{array}$ & $\begin{array}{l}\text { pària } \\
\text { ing } \\
\text { XIX }\end{array}$ & $\begin{array}{l}\text { paria } \\
\text { PORT } \\
1575\end{array}$ & $\begin{array}{l}\text { pariah } \\
\text { tâmul } \\
1613\end{array}$ & $\begin{array}{l}\text { paria } \\
\text { ing }\end{array}$ & $\begin{array}{l}\text { Paria } \\
\text { fr } \\
1745\end{array}$ \\
\hline $\begin{array}{l}\text { raja } \\
\text { sânscrito } \\
\text { XVI }\end{array}$ & rajá & $\begin{array}{l}\text { raià } \\
\text { fr } \\
1585\end{array}$ & $\begin{array}{l}\text { rajah } \\
\text { PORT } \\
1521\end{array}$ & $\begin{array}{l}\text { raja } \\
\text { PORT } \\
1.555\end{array}$ & radja & Radscha \\
\hline $\begin{array}{l}\text { sagu } \\
\text { malaio } \\
1522\end{array}$ & $\begin{array}{l}\text { sagú } \\
\text { mal } \\
1843\end{array}$ & $\begin{array}{l}\text { sagù } \\
\text { PORT } \\
1620\end{array}$ & $\begin{array}{l}\text { sagou } \\
\text { PORT } \\
1555\end{array}$ & $\begin{array}{l}\text { sago } \\
\text { PORT }\end{array}$ & $\begin{array}{l}\text { sago } \\
\text { ing }\end{array}$ & $\begin{array}{l}\text { Sago } \\
\text { ing } \\
\text { XVIII }\end{array}$ \\
\hline $\begin{array}{l}\text { sagui } \\
\text { tupi } \\
\text { XVI }\end{array}$ & zagüí & $\begin{array}{l}\text { saguino } \\
\mathrm{fr} \\
1695\end{array}$ & $\begin{array}{l}\text { sagouin } \\
\text { PORT } \\
1537\end{array}$ & $\begin{array}{l}\text { sagoin } \\
\mathrm{fr} \\
1607\end{array}$ & & \\
\hline $\begin{array}{l}\text { sarigueia } \\
\text { tupi } \\
\text { XVI }\end{array}$ & $\begin{array}{l}\text { zarigüeya } \\
\text { guar } \\
\text { XX }\end{array}$ & & $\begin{array}{l}\text { sarigue } \\
\text { PORT } \\
1578\end{array}$ & $\begin{array}{l}\text { sarigue } \\
\mathrm{fr}_{\mathrm{r}} \\
1683\end{array}$ & & \\
\hline $\begin{array}{l}\text { tamanduá } \\
\text { tupi } \\
1560\end{array}$ & $\begin{array}{l}\text { tamanduá } \\
\text { tupi } \\
1629\end{array}$ & tamanduá & $\begin{array}{l}\text { tamandua } \\
\text { PORT } \\
1603\end{array}$ & $\begin{array}{l}\text { tamandua + } \\
\text { PORT } \\
1614\end{array}$ & & $\begin{array}{l}\text { Tamandua } \\
\text { tupi } \\
1631\end{array}$ \\
\hline $\begin{array}{l}\text { tanque } \\
\text { port } \\
1497\end{array}$ & $\begin{array}{l}\text { tanque } \\
\text { PORT }\end{array}$ & $\operatorname{tank}$ & $\begin{array}{l}\text { tanque } \\
\text { PORT } \\
1617\end{array}$ & $\begin{array}{l}\text { tank } \\
\text { PORT } \\
1617\end{array}$ & $\begin{array}{l}\text { tank } \\
\text { ing }\end{array}$ & $\begin{array}{l}\text { Tank } \\
\text { ind } \\
1658\end{array}$ \\
\hline
\end{tabular}




\begin{tabular}{|c|c|c|c|c|c|c|}
\hline tapioca & tapioca & tapioca & tapioca & tapioca & tapioka & Tapioka \\
\hline tupi & tupi & $\mathrm{fr}$ & PORT & PORT/esp & ing & tupi \\
\hline 1587 & XIX & 1829 & 1651 & 1707 & & 1673 \\
\hline tapir & tapir & tapiro & tapir & tapir & tapir & Tapir \\
\hline tupi & $\mathrm{fr}$ & PORT & tupi & tupi & & tupi \\
\hline$X V I$ & 1800 & 1770 & 1558 & 1774 & 1682 & 1590 \\
\hline tatu & tatú & tatu & tatou & tatou & & Tatu \\
\hline gaur & & fr & PORT/tupi & tupi & & taino \\
\hline XVIII & & 1770 & 1553 & 1568 & & 1556 \\
\hline tufão & tifón & tifone & (tifon) & touffon & & \\
\hline ar & & $\mathrm{fr}$ & it & PORT & & \\
\hline \multirow[t]{3}{*}{1500} & & XVI & 1571 & 1588 & & \\
\hline & & & typhon & typhoon & tyfoon & Taifun \\
\hline & & & 1643 & & & 1586 \\
\hline
\end{tabular}

Povzetek

\section{RAZŠIRJANJE PORTUGALSKIH BESED, PROBLEMI IN METODE}

Avtor povzema temo, ki jo je revija načela v letniku XXVI in dopolnjuje in popravlja objavljeno; omejuje se na razširjanje portugalskih besed $v$ 17. in 18. stoletju. Upošteva tudi tiste, ki jih je portugalščina posredovala iz amerindijskih jezikov (predvsem tupi in nekoliko manj guarani). Na splošno štejejo slovarji evropskih jezikov, da so vse amerindijske besede prišle $v$ besedišča neposredno, če niso registrirane nekako pred letom 1630 . Avtor tehta vrednost argumentov, da bi lahko neki izraz označili kot izposojenko iz portugalš̌ine.

Ugotavlja, da so vse izposojenke iz eksotičnih jezikov zgolj samostalniki, po večini so to izrazi za rastline in živali. Opozarja na previdnost pri datiranju posameznih besed (npr. tufão 'tajfun' ali caravela). Ponekod je dragoceno tudi zunajjezikovno poznavanje: mais je datirano v španščini zelo zgodaj, v drugih evropskih jezikih pa kasno. Vendar ne more biti dvoma, da so to rastlino poznali: v neki knjigi izdani med leti 1516 in 1519, posvečeni cesarju Maksimilijanu I, je upodobljena tudi koruza. Zgodovinar jezika potemtakem ne more prezreti dognanj zgodovine umetnosti. 